Implementing the Dementia Early Stage Cognitive Aids New Trial (DESCANT)

intervention: mixed-method process evaluation alongside a pragmatic randomised trial

\title{
Aging and Mental Health
}

Type of article: original article

Helen Chester*, Rebecca Beresford, Paul Clarkson, Charlotte Entwistle, Vincent Gillan, Jane Hughes, Martin Orrell, Rosa Pitts, Ian Russell, Eileen Symonds, David Challis, and Members of the HoSt-D (Home Support in Dementia) Programme Management Group

*corresponding author

Helen Chester

Institute of Mental Health

The University of Nottingham

School of Medicine

Jubilee Campus

University of Nottingham Innovation Park

Triumph Road

Nottingham

NG7 2TU

helen.chester@nottingham.ac.uk

Rebecca Beresford

Social Care and Society

School of Health Sciences

Faculty of Biology, Medicine and Health

The University of Manchester

Ellen Wilkinson Building

Manchester

M15 6JA

$\underline{\text { Rebecca.beresford@manchester.ac.uk }}$

Paul Clarkson

Social Care and Society

School of Health Sciences

Faculty of Biology, Medicine and Health

The University of Manchester

Ellen Wilkinson Building

Manchester

M15 6JA

Paul.clarkson@manchester.ac.uk 
Charlotte Entwistle

Department of Psychology

Lancaster University

Fylde College

Lancaster

LA1 4YF

c.entwistle1@lancaster.ac.uk

Vincent Gillan

Formerly of Social Care and Society

School of Health Sciences

Faculty of Biology, Medicine and Health

The University of Manchester

Ellen Wilkinson Building

Manchester

M15 6JA

Vinny-gillan@live.co.uk

Jane Hughes

Institute of Mental Health

The University of Nottingham

Jubilee Campus

University of Nottingham Innovation Park

Triumph Road,

Nottingham

NG7 2TU

Jane.Hughes@nottingham.ac.uk

Martin Orrell

Institute of Mental Health

The University of Nottingham

Jubilee Campus

University of Nottingham Innovation Park

Triumph Road,

Nottingham

NG7 2TU

M.Orrell@nottingham.ac.uk

Rosa Pitts

Division of Health Research

Faculty of Health and Medicine

Lancaster University

Bailrigg

Lancaster

LA1 4YG

r.pitts1@lancaster.ac.uk 
Ian Russell

Swansea Trials Unit

Medical School

Swansea University

Swansea

Wales

SA2 8PP

i.t.russell@swansea.ac.uk

Eileen Symonds

Institute of Mental Health

The University of Nottingham

School of Medicine

Jubilee Campus

University of Nottingham Innovation Park

Triumph Road

Nottingham

NG7 2TU

Esym105248@aol.com

David Challis

Institute of Mental Health

The University of Nottingham

Jubilee Campus

University of Nottingham Innovation Park

Triumph Road,

Nottingham

NG7 2TU

David.challis@nottingham.ac.uk

\section{Acknowledgements}

The DESCANT research team acknowledges the support of the NIHR Clinical Research Network. Other members of the Programme Management Group were: Reagan Blyth (Pennine Care NHS Foundation Trust), Professor Linda Davies (University of Manchester), Dr David Jolley, Professor Narinder Kapur (University College London), Professor Fiona Poland (University of East Anglia), Professor Brenda Roe (Edge Hill University), Professor Chris Roberts and Jean Tottie (Together in Dementia Everyday). The team would also like to thank Professor Bob Woods for his assistance in developing the manual used for the DESCANT intervention and Professor Brenda Roe for her contribution to the training provided to the interviewers who collected the baseline data reported in this paper.

\section{Funding}

This study is funded by the National Institute for Health Research (NIHR) Programme Grants for Applied Research (reference number: DTC-RP-PG-0311-12003). The views expressed are those of the authors and not necessarily those of the NIHR or the Department of Health and Social Care. 


\section{Disclosure Statement}

No potential conflict of interest was reported by the authors. 


\begin{abstract}
Objectives: The DESCANT (Dementia Early Stage Cognitive Aids New Trial) intervention provided a personalised care package designed to improve the cognitive abilities, function and well-being of people with early-stage dementia and their carers, by providing a range of memory aids, together with appropriate training and support. This sub-study aimed to assess implementation and identify contextual factors potentially associated with participant outcomes.
\end{abstract}

Method: A mixed-methods approach was adopted alongside the pragmatic randomised trial. Data were obtained from intervention records and interviews with five dementia support practitioners across seven National Health Service Trusts in England and Wales. A reporting framework was constructed from available literature and data assessed by descriptive statistics and thematic analysis.

Results: Participation and engagement was high with 126 out of 128 participants completing the intervention with packages tailored to individual participants. Misplacing items and poor orientation to date and time were common areas of need. Memory aids frequently supplied included orientation clocks (91\%), whiteboards (60\%), calendars (43\%) and notebooks (32\%), plus bespoke items. Intervention duration and timing were broadly consistent with expectations. Variation reflected participants' needs, circumstances and preferences. Qualitative findings suggested a potentially positive impact on the well-being of people with dementia and their carers. Issues associated with successful roll-out of the intervention are explored in the discussion.

Conclusion: Successful implementation increased confidence in future findings of the randomised trial. Depending on these, DESCANT may prove a scalable intervention with potential to improve the function and quality of life of people with dementia and their carers.

Key words: dementia; pragmatic randomised trial; intervention; process evaluation; mixed methods 


\section{Introduction}

Worldwide it was estimated there were over 50 million people living with dementia in 2020, estimated to reach 152 million in 2050 (Alzheimer's Disease International, 2020). In 2019 there were approximately 885,000 older people with dementia in the United Kingdom (UK) and an estimated 670,000 people act as their primary carers (Alzheimer's Society, 2014a). Over twofifths of people living with dementia have mild to moderate dementia and the majority (twothirds) live in the community (Alzheimer's Society, 2014a; Wittenberg et al., 2019). The National Dementia Strategy in England and the National Dementia Vision for Wales highlighted the need for early diagnosis and were followed by a commitment to establish multidisciplinary memory clinics (Department of Health and Social Care, 2009; 2012; Welsh Assembly Government, 2011). Memory services or clinics have been defined as 'a multidisciplinary team that assesses and diagnoses dementia and may provide psychosocial interventions for dementia' (1000 Lives Improvement Service, 2014 p.7). There are estimated to be around 300 memory clinics in the UK (Moore, Goodison \& Sampson, 2019). They not only focus on diagnosis but are increasingly involved in post-diagnostic treatment and coordination of care both in the UK and internationally (Voigt-Radloff et al., 2011). Timely diagnosis is important and needs to be followed by appropriate post-diagnostic support (de Vugt and Verhey, 2013). Examples of the latter include peer groups, cognitive behaviour therapy, and financial and legal advice (Hailey et al., 2016). However, the availability of evidence-based interventions post-diagnosis has not kept up with the demand for such support (Wright et al., 2019).

Internationally, psycho-social interventions (or non-pharmacological interventions) for example art or music therapy, sensory interventions, and cognitive stimulation, are increasingly popular as an alternative or complement to pharmacological interventions for improving 
outcomes and quality of life of people with dementia and their carers (Patel et al., 2014; Clarkson et al., 2017). However, often they are implemented in clinical practice with little or no evidence of their effectiveness, giving rise to calls for rigorous studies to establish this (Orrell, 2012). In the UK and internationally, randomised trials are increasingly evidencing the positive effects of psychosocial interventions. These include their potential to improve cognition and psychosocial functioning; reduce the behavioural and psychological symptoms of dementia; improve caregivers quality of life, reduce care burden; and decrease anxiety or depressive symptoms (Berwig et al., 2017; Blom et al., 2015; Chien \& Lee, 2011; Dias et al., 2008; Livingston et al., 2014; Martini de Oliveira et al., 2015; Nordheim et al., 2019; Orrell et $a l, 2014)$.

Memory aids are commonly recommended in practice and used by people with dementia and their carers. However, robust evaluation of common memory aids like calendars, clocks, whiteboards with electric timers, and 'post-it' note dispensers is lacking, and a Cochrane review highlighted the need for a larger study of their utility (van der Roest et al., 2017). The DESCANT (Dementia Early Stage Cognitive Aids New Trial) trial was a multi-site pragmatic randomised trial, to design, implement and evaluate the clinical and cost-effectiveness of an intervention to support people with early stage dementia and their informal carers in using memory aids at home (Chester et al., 2018). This intervention could be seen as an environment and activity model of care, according the categorisation of Lord et al. (2019). Its underlying rationale is that an individual's functional decline can be influenced by the home environment and that modifications to this may help maximise their performance of daily activities or tasks. As it had a focus on identifying specific needs and setting goals to address them, it also had elements of needs and goals-based care. Both models share the underlying aim of supporting people with dementia to live with dementia at home for longer (Lord et al., 2019). 
DESCANT was designed to be cheap, realistic and scaleable. If clinically effective and costeffective, its modest nature and cost could enhance the likelihood of its incorporation into mainstream practice which would need an understanding of how it works (Chester et al., 2018). Also needed, in addition to the randomised trial, is the assessment of implementation and identification of factors potentially associated with variation in outcomes for participants (Moore et al., 2015). Process evaluation is particularly important in multi-site trials to assess whether interventions have been conducted consistently across sites (Linnan \& Steckler, 2002), and to distinguish between interventions that are inherently unsound and those that have not been implemented correctly (Oakley et al., 2006). It is important to include a process evaluation in such studies to avoid "evaluating a program that has not been adequately implemented" (Basch et al., 1985 p.315; Moore et al., 2015). Increasingly, the value of process evaluation is being recognised and evidenced in practice (Alwin et al., 2013; Voight-Radloff et al., 2011). However, process evaluations are not always undertaken, meaning that the characteristics of what makes an intervention successful are not always understood (Orrell, 2012). Qualitative work within randomised trials is required to understand how interventions work. Moreover, a clear intervention manual is needed so that interventions can be reliably replicated in practice (Orrell, 2012; Oyebode \& Parveen, 2019). Furthermore, it is important to explore possible any implementation barriers, facilitators, mediators and moderators, and the acceptability of interventions to participants (Oyebode \& Parveen, 2019; Barbosa et al., 2017; Qiu et al., 2019). There are several frameworks for process evaluations in the literature, but they are not consistent in reporting findings or defining key components, with, for example, differences in the use of terminology. There is, however, more consensus about the value of mixed-methods in process evaluation, with both quantitative and qualitative methods considered necessary to develop a more detailed and comprehensive understanding of implementation (Linnan \& Steckler, 2002; Leontjevas et al., 2012; Moore et al., 2015). 
This paper describes a process evaluation using a mixed-methods approach to assess the implementation of the DESCANT intervention and identify contextual factors associated with variations in outcomes for participants, ahead of clinical and cost-effectiveness analyses reported separately.

\section{Methods}

\section{Trial setting and recruitment}

DESCANT took place in ten NHS Trusts - nine in England and one in Wales. Each ran a memory service providing early diagnosis and support for people with dementia and their carers. Participant pairs comprised a person with mild to moderate dementia and an identified carer, recruited mainly from memory services and local research-interested lists. The target sample size, based on a power calculation, was 360 pairs (180 in the intervention group and 180 in the control group completing the final assessment) (Chester et al., 2018). Due to anticipated sample attrition, a larger number of participants (468) were recruited at baseline to achieve it. Figure 1 details the inclusion criteria and participant flow through the study, including the achieved sample size.

Following baseline assessment, 234 participant pairs were randomly assigned to the intervention group receiving the DESCANT intervention and 234 to the control group receiving treatment as usual (TAU) plus a memory handbook (Alzheimer's Society, 2014b). TAU comprised help from memory clinic staff, post diagnostic counselling and advice, and specialist follow up as appropriate. Participants were assessed again at 13 and finally 26 weeks after randomisation, for the clinical and cost-effectiveness analyses. 
Ethical approval was obtained from the National Research Ethics Service (NRES) (reference 15/NW/0822).

\section{Figure 1 CONSORT flowchart of DESCANT Trial}

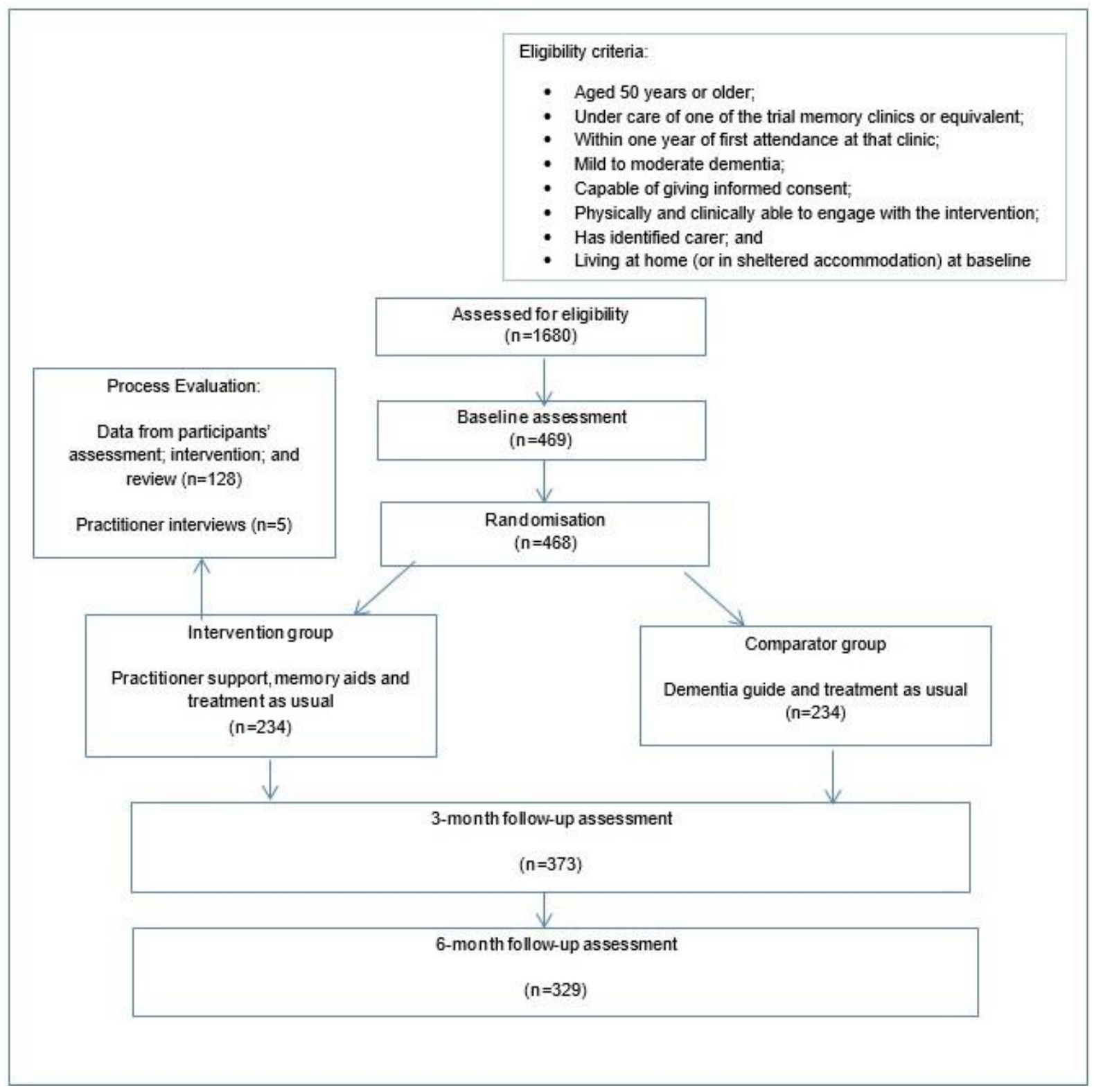

\section{Intervention}

The DESCANT intervention aimed to improve the cognitive abilities, function and well-being of people with early-stage dementia and their carers, by providing a range of memory aids, and 
training and support in their use (Chester et al., 2018). Dementia Support Practitioners (DSPs) delivered the intervention using a manual to guide each of the four sessions, with worksheets to facilitate and record delivery ('intervention record'). The aim was to deliver the first session face-to-face at home to participant pairs within two weeks of randomisation. During this session DSPs collected information about memory problems, current use of memory aids, and what goals participants would like to achieve by participating, using standardised and study specific worksheets (Chester et al., 2018). DSPs provided an appropriate pack of memory aids and support at the first session. They used core memory aids: whiteboard; clock showing day and date; post-it notes; pen and notepad; and calendar. These were selected as they are readily available at shops, were simple to install, and are relatively cheap. DSPs also had the flexibility to purchase more items within a budget of $£ 150$ per participant to tailor their intervention to individual circumstances. Additionally, they could also provide support with memory aids already in use within the home. Two telephone follow-up support sessions and a final session face to face with participants and their carers were undertaken by DSPs. Whilst the first and fourth sessions were a core part of the intervention, intermediate support sessions - telephone or face-to-face to deliver or adjust a memory aid - were optional. A further reflection of the fact this was a personalised intervention, throughout there was flexibility for participants to meet the DSP jointly or separately if they wished, and it was recognised that the extent of participation in each session could vary depending on the preferences of the person with dementia and their carer.

\section{Process evaluation design}

After recruitment began in November 2016, quantitative and qualitative data were collected, including a subset of participant baseline data from the trial itself. The process evaluation added intervention records about the provision of memory aids, and in-depth interviews with DSPs 
who delivered the interventions until 30 November 2018. This cut-off date (before recruitment to the trial was concluded) was necessary to ensure the process evaluation dataset was complete before the start of outcomes analysis, and thus to avoid biasing findings (Moore et al., 2015). Included in the process evaluation were 128 intervention records from six English sites and the Welsh site; and five qualitative interviews from four English sites. The three sites that recruited most participant pairs were included in both datasets. Trusts agreed to the qualitative research as part of the trial protocol. However, participation in interviews by DSPs was voluntary. As trial sites started recruitment at different time points, DSPs were asked to participate in the interviews if they had completed five interventions. This criterion was chosen to ensure they had sufficient experience of conducting the intervention whilst maximising participation. Six DSPs from four sites were emailed to invite them to take part in an interview. All but the DSP who left the Trust before interviews were scheduled did so. The five resulting interviews were conducted between May 2018 and November 2018.

\section{Framework for evaluation}

Informed by the literature and guidance by the Medical Research Council (MRC) (Moore et al., 2015), a reporting framework was constructed to address the study aim (Perry et al., 1997; Baranowski \& Stables, 2000; Linnan \& Steckler, 2002; Haynes et al. 2014; Hickey et al., 2016). This framework was discussed, refined and agreed with the process evaluation subgroup which oversaw this aspect of the study. This comprised three domains: context - detailing its effect on the process and outcomes; implementation - examining what was delivered and how this was achieved; and mechanisms of impact - describing participants' response to and interaction with the intervention (Moore et al., 2015) (Table 1a). Fidelity of function, namely "flexibility in how an intervention is delivered so long as it is achieving the same delivery goal each time" (Public Health England, 2018) was measured in two ways: delivery of the core 
components of the intervention (assessment, intervention and review - Figure 4 of Chester et al., 2018); and evidence that interventions were tailored to meet assessed needs. 
Table 1a Process evaluation domains, research questions, measures and data collection

\begin{tabular}{|c|c|c|c|}
\hline Process evaluation domain & Research questions & Measures or themes & Data collection (table) \\
\hline Context & $\begin{array}{l}\text { 1) In what context were interventions implemented? } \\
\text { a) What characteristics were perceived to mediate } \\
\text { outcomes and impact on implementation? } \\
\text { b) How did the intervention and use of memory aids } \\
\text { compare with Treatment as Usual? } \\
\text { c) Was there evidence of input extending beyond the } \\
\text { focus of the intervention? }\end{array}$ & $\begin{array}{l}\text { Environmental characteristics (e.g. health } \\
\text { and social care support) } \\
\text { - } \quad \text { Treatment fidelity - comparator group } \\
\text { - Treatment fidelity - intervention group }\end{array}$ & $\begin{array}{l}\text { DSP interviews (Tables 1b \& 3) } \\
\text { DSP interviews (Tables } 1 \mathrm{~b} \& 3 \text { ) } \\
\text { DSP interviews (Tables } 1 \mathrm{~b} \& 3 \text { ) }\end{array}$ \\
\hline Implementation & $\begin{array}{l}\text { 2) How was the intervention implemented } \\
\text { a) To what extent were essential components } \\
\text { delivered? } \\
\text { b) For what purpose? } \\
\text { c) What was the content of interventions as delivered? } \\
\text { d) What were the characteristics, materials and } \\
\text { structure that supported delivery? } \\
\text { 3) What were perceived facilitators and barriers to } \\
\text { implementation and effectiveness? } \\
\text { 4) What strategies were used to overcome these barriers } \\
\text { during implementation? }\end{array}$ & 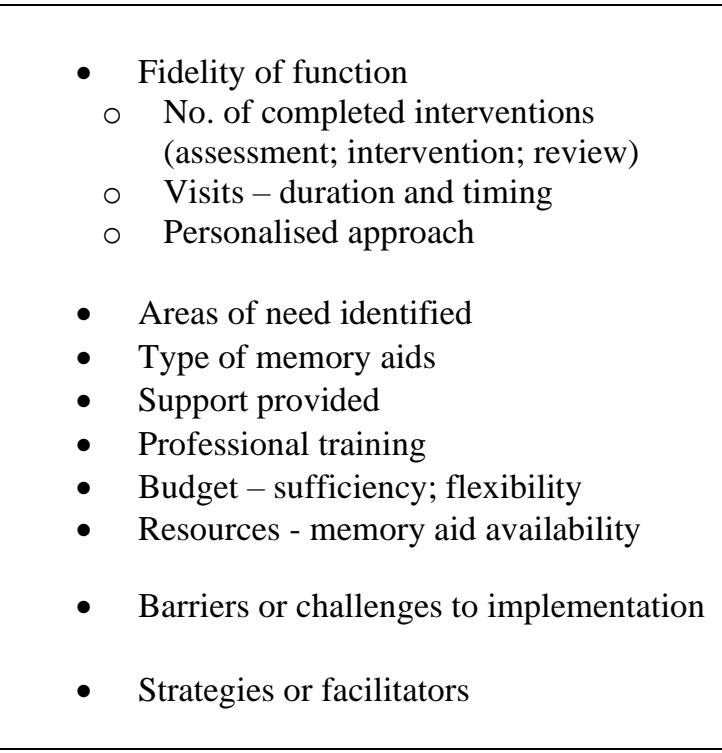 & $\begin{array}{l}\text { Intervention records (Table 4) } \\
\text { DSP interviews (Tables 1b \& 3) } \\
\text { DSP interviews (Tables 1b \& 3) } \\
\text { Intervention records (Table 5a \& 5b) } \\
\text { DSP interviews (Tables 1b \& 3) } \\
\text { DSP interviews (Tables 1b \& 3) } \\
\text { DSP interviews (Tables 1b \& 3) } \\
\text { DSP interviews (Tables 1b \& 3) } \\
\text { DSP interviews (Tables 1b \& 3) } \\
\text { DSP interviews (Tables 1b \& 3) }\end{array}$ \\
\hline Mechanisms of impact & $\begin{array}{l}\text { 5) What impact did the intervention have on participants? } \\
\text { a) What were their levels of participation? } \\
\text { b) How did patients and carers interact with the } \\
\text { intervention? } \\
\text { c) What were the effects of the intervention? } \\
\text { d) What influenced responses to the intervention? }\end{array}$ & $\begin{array}{l}\text { - Participation - session attendance } \\
\text { - Response } \\
\text { O Level of engagement } \\
\text { - } \quad \text { Visible use and integration of aids } \\
\text { - } \quad \text { Mediators or moderators }\end{array}$ & $\begin{array}{l}\text { Intervention records (Table 4) } \\
\text { Intervention records (Table 6) } \\
\text { DSP interviews (Tables } 1 \mathrm{~b} \& 3 \text { ) } \\
\text { DSP interviews (Tables } 1 \mathrm{~b} \& 3 \text { ) }\end{array}$ \\
\hline
\end{tabular}


e) Were there any unexpected effects?

Source: Adapted from Haynes et al. (2014); Moore et al. (2015) and Hickey et al. (2016). 


\section{Data analysis}

Data from the intervention records were entered into IBM SPSS statistics (version 23) and any unusual features checked with DSPs (for example an incorrect date). Derived measures were created (for example intervention length from session dates) and written information coded (such as memory aids provided) to permit quantification. Demographic characteristics were extracted from the trial baseline dataset and merged with these data. Frequency counts and measures of central tendency (mean) and spread (standard deviation) were used to characterise those receiving the intervention and its features. Digital recordings of the DSP interviews were professionally transcribed and thematic analysis undertaken using Atlas ti TM to identify the main themes. Both deductive and inductive approaches (Braun \& Clarke, 2006) were used to identify all salient themes. First, three researchers (HC, VG, RP) read transcripts from the first two interviews to establish an initial coding frame from the data. Second, the process evaluation framework (Table 1a) was mapped on to this frame to address specific research questions and facilitate synthesis of the quantitative data (Masterson-Algar et al. 2017). This coding frame was discussed and agreed with the process evaluation subgroup. Third, VG and RP used the resulting framework to code all five interview transcripts; as the last three interviews needed no new codes, they achieved data saturation (Bowen, 2008). Finally, two other members of the

research team ( $\mathrm{HC}$ and $\mathrm{CE}$ ) reviewed the data on each code in Atlas $\mathrm{ti}^{\mathrm{TM}}$ and derived all relevant themes and sub-themes at latent level beyond the semantic content of the data (Table 1b), to enhance understanding of meaning (Braun \& Clarke, 2006). 
Table 1b Process evaluation domains, themes and subthemes

\begin{tabular}{|c|c|c|}
\hline Domain & Themes & Sub-themes \\
\hline \multirow[t]{2}{*}{ Context } & $\begin{array}{l}\text { Broader contextual } \\
\text { characteristics }\end{array}$ & - Organisational setting \\
\hline & Treatment fidelity & $\begin{array}{ll}\text { - } & \text { Comparator group } \\
\text { - } & \text { Intervention group }\end{array}$ \\
\hline \multirow[t]{6}{*}{ Implementation } & Areas of need & $\begin{array}{ll}\text { - } & \text { Orientation } \\
\text { - } & \text { Misplaced items }\end{array}$ \\
\hline & Fidelity of function & $\begin{array}{ll}\text { - } & \text { Personalised approach } \\
\text { - } & \text { Ensuring fit and acceptability }\end{array}$ \\
\hline & Skills & $\begin{array}{l}\text { - Professional experience } \\
\text { - Condition-specific knowledge } \\
\text { - Personal and social skills } \\
\text { - Assessment }\end{array}$ \\
\hline & Resources & 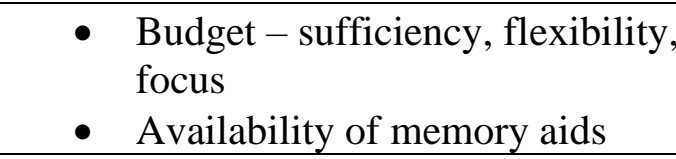 \\
\hline & Barriers and challenges & 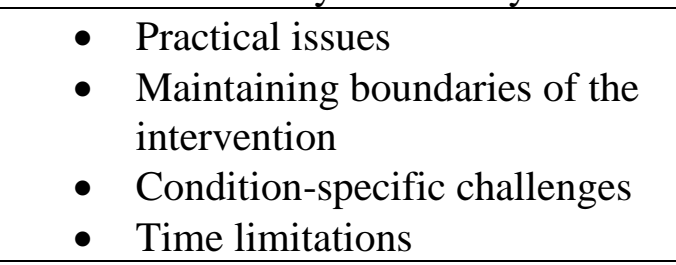 \\
\hline & Facilitators and strategies & $\begin{array}{l}\text { - } \\
\text { - Approprilising issues } \\
\text { behaviour } \\
\text { - Knowledge exchange }\end{array}$ \\
\hline \multirow[t]{3}{*}{ Mechanisms of impact } & Response & $\begin{array}{l}\text { - } \text { Positive benefits } \\
\text { - Negative feedback }\end{array}$ \\
\hline & Mediators/moderators & $\begin{array}{l}\text { - } \text { Family dynamics } \\
\text { - Carer involvement } \\
\text { - Co-morbidities } \\
\text { - Language and culture }\end{array}$ \\
\hline & Unintended effects & - Unforeseen benefits \\
\hline
\end{tabular}




\section{Findings}

Table 2 shows the demographic characteristics of the 128 intervention pairs included in the process evaluation; two of these withdrew before the intervention, one for lack of time, the other because the person with dementia declined in health. Findings are reported against the domains of the process evaluation framework (Table 1a) and DSPs identified by anonymous codes (DSP1-5), and illustrative quotes by their reference number in Table 3 (e.g Q1).

Table 2 DESCANT intervention: participant characteristics

\begin{tabular}{|c|c|c|c|}
\hline \multicolumn{2}{|c|}{ Characteristics of people with dementia } & $\mathrm{n}$ & $\%$ \\
\hline \multirow[t]{3}{*}{ Ethnicity: } & White & 114 & 89 \\
\hline & Asian or Asian British & 9 & 7 \\
\hline & Black or African or Caribbean or Black British & 5 & 4 \\
\hline \multirow[t]{2}{*}{ Gender: } & Male & 58 & 45 \\
\hline & Female & 70 & 55 \\
\hline Living wit & arer & 76 & 59 \\
\hline \multicolumn{4}{|c|}{ Relationship of carer to person with dementia } \\
\hline & Spouse or partner & 65 & 51 \\
\hline & Son or daughter & 49 & 38 \\
\hline & Other relative & 9 & 7 \\
\hline & Friend or other & 5 & 4 \\
\hline & & Mean (SD) & Range \\
\hline \multicolumn{2}{|c|}{ Age (years) } & $79.3(6.3)$ & $64-97$ \\
\hline \multicolumn{2}{|c|}{ S-MMSE score $(\mathrm{N}=126)$} & $22.9(5.2)$ & $4-30$ \\
\hline
\end{tabular}

Source: Main trial dataset. S-MMSE (Standardised Mini-Mental State Examination) Score (Molloy \& Standish, 1997). 
Table 3 Quotes illustrating themes and sub-themes

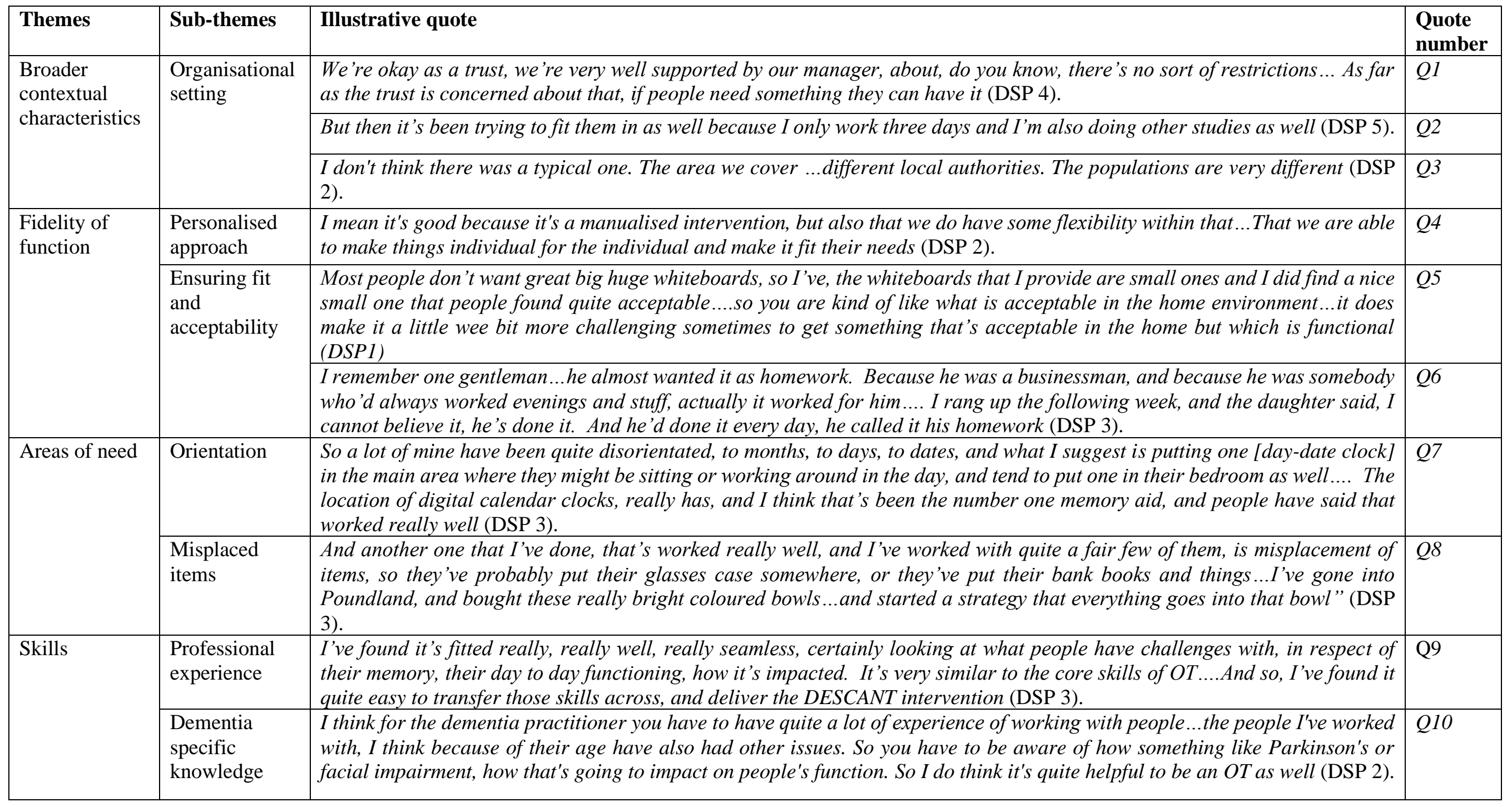




\begin{tabular}{|c|c|c|c|}
\hline & Assessment & $\begin{array}{l}\text { So if they're forgetting to make a cup of tea, so they're not making a cup of tea, is that because they've got a loss of appetite? } \\
\text { Is it because they've forgotten the steps in how to make a cup of tea?...Is it a processing thing where they forget the steps and } \\
\text { the process, or is it a visual dysfunction...?...So do you need to put the utensils and the cups and everything next to the kettle so } \\
\text { they can find it all? Or do you actually need to put an instruction list on the wall next to the kettle so they can follow the steps } \\
\text { and make their own cup of tea (DSP 1). }\end{array}$ & $Q 11$ \\
\hline \multirow[t]{5}{*}{ Resources } & \multirow[t]{3}{*}{$\begin{array}{l}\text { Budget - } \\
\text { sufficiency }\end{array}$} & $\begin{array}{l}\text { "We've got the hundred and fifty pounds per person, I don't think we've got anywhere near the hundred and fifty pounds for } \\
\text { each person that we've seen" (DSP 4) }\end{array}$ & $Q 12$ \\
\hline & & $\begin{array}{l}\text { There was one lady that I did in the very beginning, she was putting...she couldn't find things in the kitchen so I was actually } \\
\text { made some little stickers to put on the doors for her, just something really simple. From a cost wise I don't think some of the } \\
\text { interventions have been that expensive really (DSP 5). }\end{array}$ & $Q 13$ \\
\hline & & $\begin{array}{l}\text { It's not just the fact that you've got a notebook but the notebooks that we provide have, the ones I do are spiral bound so you } \\
\text { can put a pen with it so people don't have to go looking for a pen....it's the small details with the items that make the difference } \\
\text { as well (DSP 1). }\end{array}$ & $Q 14$ \\
\hline & Budget - focus & $\begin{array}{l}\text { Last week, a carer said it was really helpful that I'd said to them, rather than you tell them the time, you say, go and look at } \\
\text { your clock mum, go and do this mum....So they said, they found that really useful, that practical hands on tip..... So, although } \\
\text { you're doing the aids, there's a lot of strategy work that goes in it, like advising about approaches (DSP 3). }\end{array}$ & $Q 15$ \\
\hline & $\begin{array}{l}\text { Availability of } \\
\text { memory aids }\end{array}$ & $\begin{array}{l}\text { And the calendars that we provide, you can't buy them in the shop. We've made those ... the feedback I've had from people is } \\
\text { they like those because they've got room to write... So it might be, for example, somebody had a plumber coming but they } \\
\text { couldn't remember what the plumber was coming for... so having all of that, having space available to write that if that's needed } \\
\text { people have found helpful (DSP 1). }\end{array}$ & $Q 16$ \\
\hline \multirow[t]{2}{*}{$\begin{array}{l}\text { Barriers and } \\
\text { challenges }\end{array}$} & $\begin{array}{l}\text { Dementia } \\
\text { specific } \\
\text { challenges }\end{array}$ & $\begin{array}{l}\text { The carer had emailed me to say please don't talk about dementia, please don't talk about memory problems. So that was quite } \\
\text { challenging. It's a research project for people with dementia (DSP 2). }\end{array}$ & $Q 17$ \\
\hline & $\begin{array}{l}\text { Maintaining } \\
\text { boundaries of } \\
\text { the } \\
\text { intervention }\end{array}$ & $\begin{array}{l}\text { I think my reflections have been that it's been a really good experience. There have been some difficulties, and I think that's to } \\
\text { do with the research process of it, and the strictness of what you need to adhere to, like fidelity wise, to deliver what you should } \\
\text { deliver. And I think it's been hard for me, I've had to sit on my hands at times, where I've been really careful not to veer into } \\
\text { clinical issues, and keep on track (DSP 3). }\end{array}$ & $Q 18$ \\
\hline \multirow[t]{2}{*}{$\begin{array}{l}\text { Facilitators } \\
\text { and strategies }\end{array}$} & $\begin{array}{l}\text { Appropriate } \\
\text { discussion and } \\
\text { behaviour }\end{array}$ & $\begin{array}{l}\text { But we spent about ten minutes talking about Nigeria, because that's where they were from.... It came out through talking to } \\
\text { him about that, that he wasn't orientated to the day and the month... and like the lady who I wasn't allowed to mention dementia } \\
\text { to. We walked for ten minutes around her garden, but then it was clear she had some perceptual problems (DSP 2). }\end{array}$ & $Q 19$ \\
\hline & $\begin{array}{l}\text { Normalising } \\
\text { issues }\end{array}$ & $\begin{array}{l}\text { If people are a bit resistant to talking about difficulties, I get my phone out and go oh yeah, look at all the alerts coming up on } \\
\text { my phone. It's got a horrible pink cover, so I can always find it.... the aids that we provide.... They're not things that you don't } \\
\text { see in everyday life, so they're quite normalised. So I think people quite like that as well (DSP 2). }\end{array}$ & $Q 20$ \\
\hline
\end{tabular}




\begin{tabular}{|c|c|c|c|}
\hline \multirow[t]{3}{*}{ Response } & \multirow[t]{2}{*}{$\begin{array}{l}\text { Positive } \\
\text { benefits }\end{array}$} & $\begin{array}{l}\text { And, to be fair, most of it, I've never had one that's been negative, it's all been positive, they've really like the digital calendar } \\
\text { clock, my goodness, I could write a book about what they say about it. But, they've all been really positive about the aids (DSP } \\
\text { 3). }\end{array}$ & $Q 21$ \\
\hline & & $\begin{array}{l}\text { There was one couple, she was having a snooze in the afternoon.... and then she was waking up thinking it was the morning.... } \\
\text { She wanted to have her porridge, and her husband said, it was so frustrating that I had to... Simple little thing, and...he said } \\
\text { she's just stopped asking for porridge, because the clock says to her, it's Thursday evening, or something (DSP 4). }\end{array}$ & $Q 22$ \\
\hline & $\begin{array}{l}\text { Negative } \\
\text { feedback }\end{array}$ & $\begin{array}{l}\text { I've had a couple of people who I think perhaps didn't find it as useful as what they hoped. And my impression from those } \\
\text { couple of situations was one ... their types of dysfunction and loss of function was of a nature that was outside the scope of } \\
\text { what traditional memory aids would be able to deal with....and another scenario was where, you know the, there was an } \\
\text { extensive family network and they were providing all the support for the person with dementia (DSP 1). }\end{array}$ & $Q 23$ \\
\hline \multirow[t]{2}{*}{$\begin{array}{l}\text { Unintended } \\
\text { effects }\end{array}$} & \multirow[t]{2}{*}{$\begin{array}{l}\text { Unforeseen } \\
\text { benefits }\end{array}$} & $\begin{array}{l}\text { I think one of the outcomes of my visit was that they were going to get the father-in-law referred for an assessment as well, } \\
\text { because a lot of the equipment was quite helpful for him... And said that he was going to ask the GP for a referral to the memory } \\
\text { clinic (DSP 2). }\end{array}$ & Q24 \\
\hline & & $\begin{array}{l}\text { So quite often, especially if you've got family where you've got several carers coming in and out, they quite often end up using } \\
\text { the white boards as message boards between them so that they improve their communication to improve the support they provide } \\
\text { to the person with dementia (DSP 1). }\end{array}$ & Q25 \\
\hline \multirow[t]{3}{*}{$\begin{array}{l}\text { Mediators/mo } \\
\text { derators }\end{array}$} & $\begin{array}{l}\text { Family } \\
\text { dynamics }\end{array}$ & $\begin{array}{l}\text { There are quite often family dynamics. Sometimes it's quite awkward, the dynamics, particularly if it's a child and their } \\
\text { parent....But I mean some of the feedback from her was that sometimes family dynamics are an issue because her sister was } \\
\text { the one who provides a lot of the care but she wasn't there. So we talked about some solutions, but they weren't acceptable to } \\
\text { the sister (DSP 2). }\end{array}$ & Q26 \\
\hline & \multirow[t]{2}{*}{$\begin{array}{l}\text { Carer } \\
\text { involvement }\end{array}$} & $\begin{array}{l}\text { So it all depends on the individual and their relationship with the carer and how they work as to how the intervention best works } \\
\text { (DSP 1). }\end{array}$ & Q27 \\
\hline & & $\begin{array}{l}\text { And a lot of the carers... they're filling in the gaps for the person with dementia...there's loss of function, but it's being } \\
\text { supported, so getting a goal in that situation can be quite challenging.....So, for example, it's not unusual for a carer to have } \\
\text { taken over the bills. So the post isn't a problem. Some people have already got paid carers in their house... so cooking and... how } \\
\text { to make... food and things is not a problem (DSP 1). }\end{array}$ & Q28 \\
\hline
\end{tabular}




\section{Context}

DSP3 considered the feature of the intervention that distinguished it from treatment as usual, to be the tailored one-to-one support focussing on specific day-to-day memory problems and memory strategies, that participants would not receive as part of usual care. Sites differed in the extent to which they allowed DSPs flexibility in purchasing memory aids (Table 3 Q1); staff availability (Q2); and the diversity of participants included in the study (Q3). Some practitioners (DSPs 2, 4 and 5) raised issues about treatment fidelity. This included the need to limit the intervention to the supply of memory aids and advice even though participants could have multiple unmet needs. It was sometimes necessary for DSPs to signpost or even refer participants to other services and to follow up issues outside the intervention.

\section{Implementation}

Table 4 shows the extent to which DSPs delivered the components of the intervention and the timing and duration of visits. These findings confirmed participation was high, with almost all participants completing the intervention (the assessment in week 1; the intervention; and the review in week 4). Most participated in the optional telephone follow-up sessions. The mean interval between randomisation and the first home visit, the duration of visits, and the total duration of the intervention, were broadly consistent with the study protocol. The variation in the duration of sessions reflected the fact that this was a personalised intervention and that there was flexibility in delivery according to participants' needs, circumstances and preferences. Short home visits tended to generate longer telephone sessions between the DSP and carer. Eight participants had replaced telephone sessions with face-to-face visits, usually because DSPs had delivered additional memory aids. Variations in the timing and length of interventions typically reflected participants' circumstances and the availability of the participants and the practitioner. 


\begin{tabular}{|c|c|c|c|}
\hline \multicolumn{4}{|l|}{ Delivery } \\
\hline \multicolumn{2}{|c|}{ Number of completed interventions $(\mathrm{N}=126)$ : } & $\mathrm{n}$ & $\%$ \\
\hline \multicolumn{2}{|l|}{ Assessment } & 126 & 100 \\
\hline \multicolumn{2}{|l|}{ Intervention } & 126 & 100 \\
\hline \multicolumn{2}{|l|}{ Review } & 124 & 98 \\
\hline \multicolumn{2}{|l|}{ Complete $^{1}$} & 124 & 98 \\
\hline \multicolumn{4}{|c|}{ Optional follow up sessions $(\mathrm{N}=126)$} \\
\hline \multicolumn{2}{|c|}{ Follow up session 1} & 110 & 87 \\
\hline \multicolumn{2}{|c|}{ Follow up session 2} & 108 & 86 \\
\hline \multicolumn{2}{|c|}{ Duration of visits (minutes) } & Mean (SD) & Range \\
\hline \multicolumn{2}{|c|}{ Assessment $(\mathrm{N}=124)$} & $94.3(29.2)$ & $15-195$ \\
\hline \multicolumn{2}{|c|}{ Follow up session $1(\mathrm{~N}=102)$} & $16.8(11.0)$ & $3-60$ \\
\hline \multicolumn{2}{|c|}{ Follow up session $2(\mathrm{~N}=101)$} & $17.0(16.1)$ & $3-145$ \\
\hline \multicolumn{2}{|c|}{ Review (N=124) } & $55.1(24.6)$ & $15-120$ \\
\hline \multicolumn{2}{|c|}{ Timing of intervention after randomisation (days) } & $14.9(11.1)$ & $1-76$ \\
\hline \multicolumn{2}{|c|}{ Length of intervention: from visit 1 to visit 4 (days) } & $25.9(8.9)$ & $18-70$ \\
\hline \multicolumn{2}{|c|}{ Participation in sessions } & $\mathrm{n}$ & $\%$ \\
\hline \multirow[t]{4}{*}{ Assessment $(\mathrm{N}=126)$ : } & Person with dementia & 126 & 100 \\
\hline & Carer & 125 & 99 \\
\hline & Other family member & 25 & 21 \\
\hline & Translator (either of the above) & 4 & 3 \\
\hline \multirow{4}{*}{ Follow up session $1(\mathrm{~N}=110)^{2}$ : } & Person with dementia & 56 & 51 \\
\hline & Carer & 84 & 76 \\
\hline & Other family member & 2 & 2 \\
\hline & Translator (either of the above) & 3 & 3 \\
\hline \multirow[t]{4}{*}{ Follow up session $2(\mathrm{~N}=108)^{2}$ : } & Person with dementia & 51 & 47 \\
\hline & Carer & 83 & 77 \\
\hline & Other family member & 1 & 1 \\
\hline & Translator (either of the above) & 3 & 3 \\
\hline \multirow[t]{4}{*}{ Review (N = 124): } & Person with dementia & 123 & 99 \\
\hline & Carer & 117 & 94 \\
\hline & Other family member & 11 & 9 \\
\hline & Translator (either of the above) & 3 & 2 \\
\hline
\end{tabular}

Source: Intervention records. ${ }^{1}$ Complete: participated in all three elements - assessment; intervention; and review. ${ }^{2}$ Lower $n$ because some participants did not participate in the follow-up sessions.

Fidelity of function required DSPs to tailor the intervention to the needs and circumstances of participants. All reported taking this approach and stressed the value of having a manualised intervention with flexibility to adapt to participants' individual needs and circumstances (Table 3 Q4). Ensuring the fit and acceptability of aids and strategies to participants' circumstances emerged as a common theme. For example, DSPs saw that both memory aids (Q5) and 
strategies (Q6) had to be acceptable to participants as well as functional in their home environment. In reporting on purpose and content, all DSPs mentioned orientation to both day and date (Q7) and misplacing items (Q8) as common areas of need. These findings concur with those from the intervention records in Table 5a which showed that orientation clocks with day and date were the memory aid most frequently issued and supported. Practitioners reported issuing aids outside the core recommended toolkit (Table 5b). Further analysis revealed that just under half of participants had been provided or supported with more than one memory aid of the same type permitting their location in different places in the home. Most frequently these were orientation clocks, whiteboards or blackboards, and calendars (see table $5 \mathrm{~b}$ for example locations).

Table 5a Content of intervention for 126 recipients

\begin{tabular}{lcc}
\hline Type of memory aids provided or supported & n & \% \\
\hline Orientation clock & 115 & 91 \\
Whiteboard or blackboard & 75 & 60 \\
Calendar & 54 & 43 \\
Notepad or notebook & 40 & 32 \\
Paper notes or post-it notes & 35 & 28 \\
Catalogues or guides & 26 & 21 \\
Visual prompt signs or labels & 18 & 14 \\
Electronic devices or applications & 12 & 10 \\
Diary & 12 & 10 \\
Medication box & 7 & 6 \\
Contact details & 5 & 4 \\
Instructions or checklists & 5 & 4 \\
Organisers & 3 & 2 \\
Life history books or photo albums & 3 & 2 \\
Stimulating activities or aids & 3 & 2 \\
\hline
\end{tabular}

Source: Intervention records. 
Table 5b Memory aids - type and location

\begin{tabular}{|c|c|c|}
\hline Memory aid & Illustrative types & Location \\
\hline Orientation clock & $\begin{array}{l}\text { Analogue; Digital; Visually impaired; } \\
\text { Large text; Alarm; Watch }\end{array}$ & $\begin{array}{l}\text { Bedroom; main living area (lounge or } \\
\text { dining); kitchen; hallway; bathroom; by } \\
\text { calendar; by diary; by TV; by } \\
\text { whiteboard }\end{array}$ \\
\hline $\begin{array}{l}\text { Whiteboard or } \\
\text { blackboard }\end{array}$ & $\begin{array}{l}\text { Small or Medium or Large; A4; A3; } \\
\text { Magnetic; Day of the week }\end{array}$ & $\begin{array}{l}\text { Kitchen; main living area (lounge or } \\
\text { dining); hallway; bedroom; on the } \\
\text { fridge; internal door; by telephone; by } \\
\text { calendar; by clock }\end{array}$ \\
\hline Calendar & $\begin{array}{l}\text { A3; A4; Large print, space; Wall calendar; } \\
\text { Weekly; Monthly; Calendar 'To-do' list }\end{array}$ & $\begin{array}{l}\text { Kitchen; main living area (lounge or } \\
\text { dining); bedroom; by clock }\end{array}$ \\
\hline Notepad or notebook & $\begin{array}{l}\text { A4; A5; Magic; Clipboard; notepad; } \\
\text { Brightly coloured; Magnetic }\end{array}$ & $\begin{array}{l}\text { Kitchen; main living area (lounge or } \\
\text { dining); hallway; handbag or purse; } \\
\text { pocket; by blister pack; by telephone }\end{array}$ \\
\hline $\begin{array}{l}\text { Paper notes or post-it } \\
\text { notes }\end{array}$ & $\begin{array}{l}\text { Post-it notes; Brightly coloured; Large; } \\
\text { Lists }\end{array}$ & $\begin{array}{l}\text { Kitchen; cupboards or drawers; hallway; } \\
\text { internal doors; on whiteboard; on box } \\
\text { file; on notebook; by medication box; by } \\
\text { telephone }\end{array}$ \\
\hline Catalogues or guides & $\begin{array}{l}\text { Product catalogue; Alzheimer's society } \\
\text { memory handbook or dementia guide }\end{array}$ & - \\
\hline $\begin{array}{l}\text { Visual prompt signs or } \\
\text { labels }\end{array}$ & $\begin{array}{l}\text { Laminated cards; Stickers; Picture and } \\
\text { word signs; Name badges; Colour strips }\end{array}$ & $\begin{array}{l}\text { Internal doors; cupboards or drawers; } \\
\text { shed; bedroom; on devices; on people; } \\
\text { on oven; on photographs; on remote } \\
\text { controls }\end{array}$ \\
\hline $\begin{array}{l}\text { Electronic devices or } \\
\text { applications }\end{array}$ & $\begin{array}{l}\text { IPad; Tablet; Mobile phone; Electronic } \\
\text { timer; Gadget locator; Computer; Google } \\
\text { maps; Falls detector }\end{array}$ & Kitchen \\
\hline Diary & A4; Week-to-view diary; Pocket diary & $\begin{array}{l}\text { Main living area (lounge or dining); } \\
\text { kitchen; by telephone; by clock }\end{array}$ \\
\hline Medication box & $\begin{array}{l}\text { Blister pack; Time of day or day of week } \\
\text { packaging; Pill box or dispenser; Automatic } \\
\text { pill dispenser }\end{array}$ & Bedroom; kitchen; by clock \\
\hline Contact details & $\begin{array}{l}\text { Emergency cards; I have dementia card; } \\
\text { Laminated; Contact list or book }\end{array}$ & Handbag or purse; fridge; by telephone \\
\hline Instructions or checklists & $\begin{array}{l}\text { Laminated instructions; Recipe cards; } \\
\text { Pictorial checklists; Laminated checklists }\end{array}$ & $\begin{array}{l}\text { Internal doors; wall; by TV; next to } \\
\text { microwave; by front door }\end{array}$ \\
\hline Organisers & $\begin{array}{l}\text { Hard box file; tray; colourful visual bowls; } \\
\text { basket }\end{array}$ & $\begin{array}{l}\text { Main living area (lounge or dining); } \\
\text { bedroom }\end{array}$ \\
\hline $\begin{array}{l}\text { Life history books or } \\
\text { photo albums }\end{array}$ & $\begin{array}{l}\text { Life history or story book; Photo albums; } \\
\text { Photo display }\end{array}$ & Bedroom \\
\hline $\begin{array}{l}\text { Stimulating activities or } \\
\text { aids }\end{array}$ & $\begin{array}{l}\text { Spanish learning book or CD; Puzzle or } \\
\text { colouring books; }\end{array}$ & - \\
\hline
\end{tabular}

Source: Intervention records. 


\section{Facilitating the intervention}

Skills were one of the most salient themes emerging from the analysis. DSPs considered that their role required training and experience, notably knowledge and understanding of dementia, including assessment pathways, support and services; and improving the well-being of people with dementia and their carers. As levels of awareness, insight, and willingness to discuss the condition openly varied considerably amongst participants, DSPs needed to be alert to this. Though professional training was not a formal requirement for DSPs, four of the five practitioners were qualified occupational therapists and viewed this as advantageous (Table 3 Q9 and Q10). DSPs viewed good personal and social skills as essential, as they had to build rapport quickly with the people with dementia, their carers and wider families, implement the intervention effectively, and measure its effect. They also valued counselling skills and the ability to engage with all parties and balance their perspectives in a sensitive and fair way. Practitioners were aware that they were visiting participants at a sensitive time shortly after diagnosis of dementia, and that on entering their home environment, they had to navigate existing family dynamics and routines. They saw as essential skills: the ability to take an individualised and sensitive approach; to use humour appropriately; to treat participants with dignity; and to respect their privacy when installing memory aids and monitoring their use.

Unsurprisingly, DSPs all identified the assessment of need as a key activity and recognised the importance of relevant skills for this. They wanted to be thorough, attentive to detail, and able to collate and assess different (and potentially conflicting) sources of information, including the perspectives of the person with dementia and carer and observations of the home environment. For example, "You have to be quite good at quickly putting the pieces of the puzzle together" (DSP1). The ability to observe individuals in their home environment helped them to assess the cause of dysfunction, to identify a solution, and to monitor its effectiveness 
(Q11). They also recognised the importance of adopting a holistic approach to assessment, taking account of the existing skills, routines and coping strategies of participants.

All DSPs considered the available budget to be more than enough to fund items purchased (Q12) and they valued being able to use the budget flexibly (DSP3). Memory aids were often simple and inexpensive (e.g. prompt signs and paper notes - Table 5a). Despite their low cost they were considered effective (Q13), permitting an individualised response to identified need within budget. They viewed attention to detail when purchasing items as essential to making a real difference without increasing cost (Q14). Though their focus was on the provision of memory aids, they recognised that participants also valued strategies and advice, underpinning the importance of funding practitioner time for this when implementing interventions (Q15). However, the availability of memory aids to purchase was sometimes an issue. The timeliness and ease with which equipment could be supplied to those with specific requirements, depended on the purchasing method employed by the Trust and the stock available. Standard equipment purchased by the Trust did not always meet the needs of specific groups, for example those with a visual impairment, requiring them to buy alternatives (DSP2). Sometimes practitioners made bespoke items (Q16) or adapted items available from shops (Q8).

DSPs identified several barriers and challenges to implementing the intervention, many of which were specific to dementia. Some participants felt they had minor needs not requiring support (DSP1). Others were unaware of or unwilling to discuss their condition (Q17). Both made it more difficult to identify areas of need and establish benchmarks to measure progress. Some practitioners also reported challenges in maintaining both the boundaries of the intervention and professional boundaries whilst building rapport with participants. For example, participants sometimes perceived the intervention as a social visit (DSP5) or had multiple needs that were not appropriate to be addressed through the intervention, such as those 
relating to physical health (DSP4). Those with a clinical background found it particularly difficult to keep within the limits of the intervention (Q18). This issue was addressed through line management arrangements and the requirement for DSPs to signpost participants to other sources of appropriate help and support. The ability to sensitively build rapport and make observations based on informal practical assessment of skills and abilities in context, enabled DSPs to engage with participants in an appropriate way, and to navigate around limited insight or lack of willingness to share details of their condition. For example, one informal discussion about family history, and another walk around a garden, revealed concerns about orientation and perception (Q19). The fact that the aids were basic and readily available in shops helped to normalise their use (Q20). DSPs referred to the mutual exchange of knowledge. DSPs were educating participants, and honest feedback from participants about the usability and usefulness of memory aids and strategies was important in enabling practitioners to evaluate effectiveness and make adjustments. Information from participants about existing strategies, and what had worked as part of the intervention, gave DSPs a wider perspective (DSP4).

\section{Mechanisms of impact}

Most people with dementia and their carers participated in both home visits (Table 4). All participated in the first session (assessment) with only two not participating in the final home visit (review). Other family members were often present at home visits and occasionally a translator. Carers were more likely than people with dementia to participate in the telephone support sessions, as the person with dementia sometimes found telephone contact difficult. Twenty-six participants $(21 \%)$ received at least one additional contact (either face to face or via email) above the four planned sessions; seven of these followed the 'final' session. Reasons for this included delivery of additional memory aids and signposting to other sources of support. 
Both people with dementia and their carers engaged well with the intervention (Table 6). Most participants $(98 \%)$ were using the memory aids and had integrated them into their routines. Participants provided positive feedback to DSPs about the memory aids, particularly the orientation clock, whiteboards and calendars (Q21). They reportedly improved participants' daily living, encouraged independence, and reduced reliance on their carer (Q22). Benefits extended beyond the items themselves: particularly valued were social interaction with someone external to the caring relationship (DSP2) and the opportunity for carers to discuss dementia and its impact (DSP4). Most participants apparently received the intervention well and gave little negative feedback (Q23). Unforeseen benefits included the recognition of undiagnosed memory issues in a member of the participant's family (Q24) and the use of memory aids by other carers or family members to coordinate care (Q25).

\section{Table 6: Impact of intervention on 126 recipients}

\begin{tabular}{lcc}
\hline Engagement and use of memory aids & & \\
\hline Level of engagement by person with dementia $^{1}(\mathrm{~N}=123)$ & Mean (SD) & Range \\
& $85.5(17.0)$ & $30-100$ \\
Interest & $88.8(15.0)$ & $10-100$ \\
Response & $84.0(19.0)$ & $5-100$ \\
Initiation & $84.9(17.2)$ & $5-100$ \\
Participation & $83.5(20.9)$ & $0-100$ \\
Enjoyment & $85.3(16.0)$ & $10-100$ \\
Overall level of engagement & & \\
Level of engagement by carer $(\mathrm{N}=123)$ & $91.1(13.4)$ & $28-100$ \\
Overall level of engagement & & \\
DSP observations & 79 & $\%$ \\
Visible evidence of use of aids ${ }^{2}(\mathrm{~N}=121)$ & 40 & 65 \\
Clear evidence & 2 & 2 \\
To some extent & & \\
Not at all & 66 & 54 \\
Integration of aids into daily routine ${ }^{3}(\mathrm{~N}=122)$ & 54 & 44 \\
Fully & 2 & 2 \\
To some extent & & \\
Not at all & & \\
\hline
\end{tabular}

Source: Intervention records.

${ }^{1}$ Adapted from McDermott, Orrell \& Ridder (2015);

${ }^{2}$ In reply to 'Was there visible evidence of the patient using the memory aids?;

${ }^{3}$ In reply to 'To what extent are memory aids integrated into their daily routine?'. 
DSPs identified several potential mediators and moderators of the effects of the intervention. They considered that existing family dynamics and circumstances influenced both the delivery and effect of the intervention (Q26). All DSPs recognised carers' engagement with the intervention as having a mediating influence, particularly where the person with dementia lacked insight or willingness to discuss difficulties (Q27), or existing informal and paid support limited what could be addressed, for example opportunities to regain or retain independence (Q28). DSPs provided examples of co-morbidities which required them to respond appropriately in order to deliver the intervention, for example by avoiding telephone communication when a participant or carer had hearing difficulties; and by providing memory aids like appropriate clocks for those with visual impairments. DSPs also reported the importance of being sensitive to participants' culture and language, for example by checking their understanding of questions during the assessment before the intervention and subsequent communications.

\section{Discussion}

This evaluation confirmed successful implementation of the DESCANT intervention, thus increasing confidence in the future findings of the associated trial. If there were no apparent benefit from the intervention, poor implementation cannot be a contributing factor. Mixedmethods were used to assess the implementation of the intervention, and identify factors potentially associated with variation in outcomes for participants (Moore et al., 2015). Findings suggested the intervention was well received with high participation. Duration and timing were broadly consistent with the study protocol with variations reflecting personal circumstances. Skills, experience, and understanding of dementia by the DSP were important facilitators. The principal factors associated with variation in outcomes were family dynamics, participants' circumstances, and carers' engagement. Additional factors included local purchasing arrangements, staff availability, and unmet need. 
The process evaluation collected and reported quantitative data using a framework developed from existing literature and guidance from the MRC. This is useful as there is no consistent guidance for conducting process evaluations in non-pharmaceutical trials (Linnan \& Steckler, 2002; Moore et al., 2015). The design and use of an intervention manual (Chester et al., 2018) enhanced consistency of delivery and data collection across participants and sites and provided a means of replicating the intervention in future if shown effective in the trial (Orrell, 2012). Indeed, DSPs provided valuable information on factors facilitating and impeding implementation and examples of strategies used to overcome challenges. However, the process evaluation had two limitations. First, only DSPs contributed - by completing intervention records and participating in qualitative interviews; the research team judged that asking people with dementia and their carers to contribute process data was too much to add to the four-week intervention and research interviews. This decision was taken by researchers considering interview duration, respondent burden, and potential impact on the trial attrition rate (Hoogendoorn \& Sikkel, 1998). Subsequently, the appropriateness of this decision was confirmed through other research undertaken as part of the trial, which noted a reluctance amongst, and difficulties experienced by, participants when talking about day-to-day feelings and experiences (Abendstern et al., 2019a). Second, the need to complete the process evaluation before the trial, limited the number of participants and sites that could be included. Fortunately, it was possible to include seven of the ten sites, including the three that recruited most participants, and achieve data saturation when analysing DSP interviews. Issues relevant to the implementation of such an intervention are discussed below.

One of the reasons for the intervention's success was its timeliness, offering support soon after participants' diagnosis of dementia. This engendered positive responses from DSPs and good engagement from people with dementia and their carers. Furthermore, the design and delivery 
of the intervention was based on several principles seen as underpinning support for people living with dementia at home. Its central focus was upon the needs and goals of those people and their family carers (Lord et al., 2019), valued by both DSPs and participants.

The Care Act 2014 seeks holistic care that is acceptable to patients and responsive to their needs, circumstances and wishes. It is also important for them to participate in decisions about their care while balancing their wellbeing and that of carers (Department of Health and Social Care, 2018). The DESCANT package of memory aids and strategies, and its manner of delivery, fulfilled these principles and transcended the provision of individualised memory aids. Acceptability of interventions was measured and confirmed in this study and emerged as a major theme in the qualitative analysis. A judgement by participants and others whether intervention procedures are fair and appropriate for the problem and participants, acceptability is often underreported. In assessing this it is important that the intervention was implemented as planned (Qiu et al., 2019 p.2). This highlights the importance of assessing both implementation fidelity and acceptability. Thus, the DESCANT evaluation has provided valuable insights into measuring treatment fidelity in personalised interventions, largely absent from existing literature.

A key issue in this study was that DSPs sometimes found it difficult to keep their support within the boundaries of the intervention, not surprising when individuals have multiple needs. There was evidence of issues that were not currently being addressed, evidenced by the need for DSPs to signpost or refer individuals to other sources of support. One example was the need for equipment for those needing help with mobility around the kitchen. Unmet physical needs and lack of mobility can affect both delivery and success of interventions by placing limits on what goals can be addressed or equipment used (Challis et al., 2009). Several international studies 
have confirmed the high prevalence of unmet needs amongst people with dementia, imposing greater burden on their carers and reducing their ability to live at home (Black et al., 2013; Eichler et al., 2016; British Psychological Society, 2018; Gaugler, Kane, Kane \& Newcomer, 2005; Mazurek, Szcześniak, Urbanska, Drőes \& Rymaszewska, 2019; Zwingmann et al., 2019).

It is important that future studies take a holistic approach to the design and delivery of interventions to provide appropriate care and support, improve intervention success and take account of other unmet needs. DESCANT addressed needs in participants' daily routine and home environment that may not have been met through existing support, potentially enabling them to remain at home for longer. Echoing other research findings, this evaluation also suggested that interventions should address the effects of common co-morbidities (for example sensory impairments) (Jeon et al., 2018; 2019; Regan et al., 2019). In confirming that support for physical needs may prevent or delay mental decline, it highlighted the importance of recognising this in the design of future interventions. Irrespective of the findings of the trial, the findings of the process evaluation could inform roll out of the intervention possibly by the voluntary sector working in partnership with memory clinics (Abendstern et al. 2019b). These findings highlight relevant issues for consideration in doing this.

\section{Conclusion}

The DESCANT intervention was well implemented and valued by people with early stage dementia and their carers. It demonstrated that a successful intervention requires a broad perspective of need and takes account of co-morbidities experienced by people with dementia. Irrespective of the outcome of the trial, this process evaluation may guide how to conduct similar interventions in future. 


\section{$\underline{\text { References }}$}

1000 Lives Improvement Service. (2014). Wales National Audit Memory Clinic and Memory Assessment Services, August 2014, Cardiff: 1000 Lives Improvement Service, Public Health Wales.

Abendstern, M., Davies. K., Poland, F., Chester, H., Clarkson, P., Hughes, J., Sutcliffe, C., \& Challis, D. (2019a). Reflecting on the research encounter for people in the early stages of dementia: lessons from an embedded qualitative study. Dementia, https://doi.org/10.1177/1471301219855295.

Abendstern, M., Jasper, R., Hughes, J., Loynes, N., Sutcliffe, C., \& Challis, D. (2019b). Care coordination for older people in England: Does context shape approach? Journal of Social Work, 19 (4), 427-449.

Alwin, J., Persson, J., \& Krevers, B. (2013). Perception and significance of an assistive technology intervention - the perspectives of relatives of persons with dementia. Disability and Rehabilitation, 35 (18), 1519-1526.

Alzheimer's Society. (2014a). Dementia 2014: opportunity for change. London: Alzheimer's Society.

Alzheimer's Society. (2014b). The memory handbook: a practical guide to living with memory problems. London: Alzheimer's Society. 
Alzheimer's Disease International. (2020). From Plan to Impact III: Maintaining dementia as a priority in unprecedented times. London: Alzheimer's Disease International.

Basch, C. E., Sliepcevich, E. M., Gold, R. S., Duncan, D. F., \& Kolbe, L. J. (1985). Avoiding Type III errors in health education program evaluations: a case study. Health Education Quarterly, 12(4), 315-331.

Baranowski, T. \& Stables, G. (2000). Process Evaluation of the 5-a-day projects. Health Education and Behavior, 27(2), 157-166.

Barbosa, A., Nolan, M., Sousa, L., \& Figueiredo, D. (2017). Implementing a psychoeducational intervention for care assistants working with people with dementia in aged-care facilities: facilitators and barriers. Scandinavian Journal of Caring Sciences, 31(2), 222-231.

Berwig, M., Heinrich, S., Spahlholz, J., Hallensleben, N., Brahler, E. \& Gertz, H-J. (2017). Individualized support for informal caregivers of people with dementia - effectiveness of the German adaptation of REACH II. BMC Geriatrics, 17(1), 286.

Black, B., Johnston, D., Rabins, P., Morrison, A., Lyketsos, C., \& Samus, Q. (2013). Unmet needs of community-residing persons with dementia and their informal caregivers: findings from the maximizing independence at home study. Journal of the American Geriatric Society, 61(12), 2087-2095. 
Blom, M., Zarit, S., Groot Zwaaftink, R., Cuijpers, P. \& Pot, A. (2015) Effectiveness of an internet intervention for family caregivers of people with dementia: results of a randomised controlled trial, PLoS One, 10(2), e0116622, doi:10.1371/ journal.pone.0116622.

Bowen, G. A. (2008). Naturalistic inquiry and the saturation concept: a research note. Qualitative Research, 8(1), 137-152.

Braun, V. \& Clarke, V. (2006). Using thematic analysis in psychology. Qualitative Research in Psychology, 3(2), 77-101.

British Psychological Society. (2018). Evidence briefing: 'behaviour that challenges' in dementia. Leicester: British Psychological Society.

Challis, D., Sutcliffe, C., Hughes, J., von Abendorff, R., Brown, P. \& Chesterman, J. (2009). Supporting People with Dementia at Home: Challenges and Opportunities for the 21st Century. London: Routledge.

Chester, H., Clarkson, P., Davies, L., Hughes, J., Islam, M. S., Kapur, N., Orrell, M., Peconi, J., Pitts, R., Poland, F., Russell, I., Challis, D., \& HoSt-D (Home Support in Dementia) Programme Management Group (2018). Cognitive aids for people with early stage dementia versus treatment as usual (Dementia Early Stage Cognitive Aids New Trial [DESCANT]): study protocol for a randomised controlled trial. Trials, 19(546), 546, 1-11. 
Chien, W. \& Lee, I. (2011) Randomised controlled trial of a dementia care programme for families of home-resided older people with dementia. Journal of Advanced Nursing, 67(4), 774-787.

Clarkson, P. Hughes, J., Xie, C., Larbey, M., Roe, B., Giebel, C., Jolley, D., Challis, D., \& Members of the HoSt-D (Home Support in Dementia) Programme Group. (2017). Overview of systematic reviews: effective home support in dementia care, components and impacts stage 1, psychosocial interventions for dementia. Journal of Advanced Nursing, 73(12), 28452863.

Department of Health and Social Care. (2009). Living well with dementia: a national dementia strategy. London: Department of Health and Social Care.

Department of Health and Social Care. (2012). Prime Minister's Challenge on Dementia: delivering major improvements in dementia care and research by 2015. London: Department of Health and Social Care.

Department of Health and Social Care (2018) Care and Support Statutory Guidance. Available at https://www.gov.uk/government/publications/care-act-statutory-guidance/care-andsupport-statutory-guidance (last updated 26 October 2018; last accessed 28 February 2020).

de Vugt, M. \& Verhey, F. (2013). The impact of early dementia diagnosis and intervention on informal caregivers. Progress in Neurobiology, 110, 54-62. 
Dias, A., Dewey, M., D’Souza, J., Dhume, R., Motghare, D., Shaji, K., Menon, R., Prince, M., \& Patel, V. (2008). The effectiveness of a home care program for supporting caregivers of persons with dementia in developing countries: a randomised controlled trial from Goa, India. PLoS One 3(6): e2333. doi: 10.1371/journal.pone.0002333.

Eichler, T., Thyrian, J., Hertel, J., Richter, S., Wucherer, D., Michalowsky, B., Teipel, S., Kilimann, I., Dreier, A., \& Hoffmann, W. (2016). Unmet Needs of Community-Dwelling Primary Care Patients with Dementia in Germany: Prevalence and Correlates. Journal of Alzheimers Disease, 51(3), 847-855.

Gaugler, J., Kane, R., Kane, R., \& Newcomer, R. (2005). Unmet care needs and key outcomes in dementia, Journal of the American Geriatric Society, 53(12), 2098-2105.

Hailey, E., Hodge, S., Burns, A., \& Orrell, M. (2016). Patients' and carers' experiences of UK memory services, International Journal of Geriatric psychiatry, 31(6), 676-680.

Haynes, A., Brennan, S., Carter, S., O’Connor, D., Schneider, C. H., Turner, T., Gallego, G., \& the CIPHER Team. (2014). Protocol for the process evaluation of a complex intervention designed to increase the use of research in health policy and program organisations (the SPIRIT study). Implementation Science, 9, 113.

Hickey, G., McGilloway, S., Furlong, M., Leckey, Y., Bywater, T., \& Donnelly, M. (2016). Understanding the implementation and effectiveness of a group-based early parenting intervention. BMC Health Services Research, 16, 490. 
Hoogendoorn, A. \& Sikkel. (1998). Response burden and panel attrition. Journal of Official Statistics, 14(2), 189-205.

Jeon, Y-H., Clemson, L., Naismith, S., Mowszowski, L., McDonagh, N., Mackenzie, M., Dawes, C., Krein, L. \& Szanton, S. (2018). Improving the social health of community-dwelling older people living with dementia through a reablement program, International Psychogeriatrics, 30(6), 915-920. doi:10.1017/S1041610217001533.

Jeon, Y-H., Krein, L., Simpson, J., Szanton, S., Clemson, L., Naismith, S., Low, L-F., Mowszowski, L., Gonski, P., Norman, R., Gitlin, L. \& Brodaty, H. (2019) Feasibility and potential effects of interdisciplinary homebased reablement program (I-HARP) for people with cognitive and functional decline: a pilot trial, Aging \& Mental Health, DOI: 10.1080/13607863.2019.1642298.

Leontjevas, R., Gerritsen, D., Koopmans, R., Smalbrugge, M., \& Vernooij-Dassen, M. (2012). Process evaluation to explore internal and external validity of the "act in case of depression" care program in nursing homes. Journal of the American Medical Directors Association, 13(5), 488.e1-488.e8.

Linnan, L. \& Steckler, A. (2002). Process evaluation for public health interventions and research: an overview. In A. Steckler \& L. Linnan (Eds.), Process Evaluations for Public Health Interventions and Research (pp.1-23). San Francisco: Wiley

Livingston, G., Barber. J., Rapaport, P., Knapp, M., Griffin, M., King, D., Romeo, R., Livingston, D., Mummery, C., Walker, Z., Hoe, J., \& Cooper, C. (2014). Long-term clinical 
and cost-effectiveness of psychological intervention for family carers of people with dementia: a single-blind, randomised, controlled trial. Lancet Psychiatry, 1(7), 539-548.

Lord, K., Beresford-Dent, J., Rapaport, P., Burton, A., Leverton, M., Walters, K., Lang, I., Downs, M., Manthorpe, J., Boex, S., Jackson, J., Ogden, M., \& Cooper, C. (2019). Developing the new interventions for independence in dementia study (NIDUS) theoretical model for supporting people to live well with dementia at home for longer: a systematic review of theoretical models and randomised controlled trial evidence. Social Psychiatry and Psychiatric Epidemiology, 1(7), 539-548.

Martini de Oliveira, A., Radanovic, M., Cotting Homem de Mello, P., Buchain, P., Vizzotto, A., Celestino, D., Stella, V., Piersol, C., \& Forlenza, O. (2015). Nonpharmacological Interventions to Reduce Behavioral and Psychological Symptoms of Dementia: A Systematic Review. BioMed Research International, 2015, 218980.

Masterson-Algar, P., Burton, C., Brady, M. C., Nicoll, A., Clarke, C. E., Rick, C, Hughes, M., Au, P., Smith, C., \& Sackley, C. (2017). The PD COMM trial: a protocol for the process evaluation of a randomised trial assessing the effectiveness of two types of SLT for people with Parkinson's disease. Trials, 18(397), 1-8.

Mazurek, J., Szcześniak, D., Urbańska, K., Dröes, R-M., \& Rymaszewska, J. (2019). Met and unmet care needs of older people with dementia living at home: Personal and informal carers' perspectives. Dementia , 18(6), 1963-1975.

McDermott O., Orrell, M., \& Ridder, HM. (2015). The development of Music in Dementia 
Assessment Scales (MiDAS). Nordic Journal of Music Therapy, 24(3), 232-51.

Molloy. D. \& Standish, T. (1997). Mental status and neuropsychological assessment: a guide to the Standardised Mini-Mental State Examination, International Psychogeriatrics, 9, 87-94.

Moore, G. F., Audrey, S., Barker, M., Bond, L., Bonell, C., Hardeman, W., Moore, L., O'Cathain, A., Tinati, T., Wight, D., \& Baird, J. (2015). Process evaluation of complex interventions: Medical Research Council guidance. BMJ, 350.

Moore, K., Goodison, H., \& Sampson, E. (2019). The role of the memory service in helping carers prepare for end of life: a mixed methods study, International Journal of Geriatric Psychiatry, 34 (2), 360-368.

Nordheim, J., Hausler, A., Yasar, S., Suhr, R., Kuhlmey A., Rapp, M., \& Gellert, P. (2019). Psychosocial intervention in couples coping with dementia led by a psychotherapist and a social worker: the DYADEM trial. Journal of Alzheimer's Disease, 68 (2), 745-755.

Orrell, M. (2012) The new generation of psychosocial interventions for dementia care. The British Journal of Psychiatry, 201 (5), 342-343.

Orrell, M., Aguirre, E., Spector, A., Hoare, Z., Woods, R., Streater, A., Donovan, H., Hoe, J., Knapp, M., Whitaker, C., \& Russell, I. (2014). Maintenance cognitive stimulation therapy for dementia: single-blind, multicentre, pragmatic randomised controlled trial. The British Journal of Psychiatry, 204 (6), 454-461. 
Oyebode, J. \& Parveen, S. (2019). Psychosocial interventions for people with dementia: an overview and commentary on recent developments. Dementia, 18 (1), 8-35.

Oakley, A., Strange, V., Bonell, C., Alplen, E., Stephenson, J., \& RIPPLE Study Team. (2006). Process evaluation in randomised controlled trials of complex interventions. BMJ, 332(7538), 413-416.

Patel, B., Perera, M., Pendleton, J., Richman, A., \& Majumdar, B. (2014). Psychosocial interventions for dementia: from evidence to practice. Advances in Psychiatric Treatment, 20 (5), 340-349.

Perry, C., Sellers, D., Johnson, C., Pedersen, S., Bachman, K., Parcel, G., Stone, E., Luepker, R., Wu, M., Nader, P., \& Cook, K. (1997). The child and adolescent trial for cardiovascular health $(\mathrm{CATCH})$ : Intervention, implementation and feasibility for elementary schools in the United States. Health Education and Behaviour, 24(6), 716-735.

Public Health England. (2018). Guidance: Process Evaluation. https://www.gov.uk/government/publications/evaluation-in-health-and-well-beingoverview/process-evaluation [Accessed 4 October 2019].

Qiu, D., Hu, M., Yu, Y., Tang, B., \& Xiao, S. (2019). Acceptability of psychosocial interventions for dementia caregivers: a systematic review. BMC Psychiatry, 19(23), 1-14.

Regan, J., Frison, E., Collin, F., Dawes, P., Hann, M., Himmelbach, I., Hooper, E., Reeves, D., Simkin, Z., Thodi, C., Yang, F., Leroi, I., \& the SENSE-Cog Trial Development Team. (2019). 
Individualised sensory intervention to improve quality of life in people with dementia and their companions (SENSE-Cog trial): study protocol for a randomised controlled trial. Trials, 20(1): 80.

van der Roest, H., Wenborn, J., Pastink, C., Dröes, R. \& Orrell, M. (2017). Assistive technology for memory support in dementia. Cochrane Database Systematic Reviews. 6, CD009627.

Voigt-Radloff, S., Graff, M., Leonhart, R., Schornstein, K., Jessen, F., Bohlken, J., Metz, B., Fellgiebel, A., Dodel, R., Eschweiler, G., Vernooij-Dassen, M., Olde Rikkert, M., \& Hüll, M. (2011). A multicentre RCT on community occupational therapy in Alzheimer's disease: 10 sessions are not better than one consultation. BMJ Open; 1(1), e000096.

Welsh Assembly Government. (2011). National Dementia Vision for Wales: Dementia Supportive Communities. Cardiff: Welsh Assembly Government/Alzheimer's Society.

Wittenberg, R., Hu, B., Barraza-Araiza, L. \& Rehill, A. (2019). Projections of older people with dementia and costs of dementia care in the United Kingdom, 2019-2040. London: Care Policy and Evaluation Centre, LSE.

Wright, J., Foster, A., Cooper, C., Sprange, K., Walters, S., Berry, K., Moniz-Cook, E., Loban, A., Young, T., Craig, C., Dening, T., Lee, E., Beresford-Dent, J., Thompson, B., Young, E., Thomas, B., \& Mountain, G. (2019). Study protocol for a randomised controlled trial assessing 
the clinical and cost-effectiveness of the Journeying through Dementia (JtD) intervention compared to usual care. BMJ Open, 9(9), e029207.

Zwingmann, I., Michalowsky, B., Esser, A., Kaczynski, A., Monsees, J., Keller, A., Hertel, J., Wucherer, D., Thyrian, J., Eichler, T., Kilimann, I., Teipel, S., Wolfgramm, A., \& Hoffmann, W. (2019). Identifying Unmet Needs of Family Dementia Caregivers: Results of the Baseline Assessment of a Cluster-Randomized Controlled Intervention Trial. Journal of Alzheimer's Disease, 67 (2), 527-539. 